\title{
Respiratory diseases morbidity and mortality among adults attending a tertiary hospital in Nigeria*,
}

\author{
Morbidade e mortalidade relacionadas a doenças respiratórias \\ em adultos atendidos em um hospital terciário na Nigéria
}

\author{
Olufemi Olumuyiwa Desalu, Joshua Afolayan Oluwafemi, Ololade Ojo
}

\begin{abstract}
Objective: To determine the morbidity and mortality related to respiratory diseases among adults attending a tertiary-care hospital in Nigeria. Methods: We carried out a retrospective study of 183 adult patients ( $>15$ years of age), diagnosed with respiratory diseases between November of 2006 and October of 2008 at the Federal Medical Centre in 1do-Ekiti, Nigeria. Results: Of the 183 patients enrolled in the study, 78 (42.6\%) were male and 105 (57.4\%) were female, the male:female ratio being 1:1.4. Respiratory diseases were predominant in the 25-44 year age bracket (37.2\%) and lower socioeconomic class (81.4\%). Pulmonary TB was the leading cause of morbidity (in 42.1\%), followed by asthma (in 17.5\%) and pneumonia (in 15.3\%). Lung cancer was uncommon (in only $0.6 \%$ ). Pulmonary TB was the leading cause of hospitalization for respiratory disease (in 32\%). Pulmonary TB, asthma, pneumonia and pleural pathologies were more common in women, whereas COPD was more common in men. The most common comorbidity was HIV infection (in 11.5\%). The overall mean length of hospital stay was 14 days. Overall mortality was $8.7 \% ; 50 \%$ of the deaths were attributed to pulmonary TB, 25\% were attributed to pleural disease, $12.5 \%$ were attributed to pneumonia, and 6.25\% were attributed to acute exacerbation of COPD. Mortality was higher in women and in the 25-44 year age bracket. Conclusions: Pulmonary TB, asthma and pneumonia were the leading causes of respiratory disease-related morbidity. Pulmonary TB was the leading cause of respiratory disease-related mortality among the adult Nigerians evaluated. Therefore, these conditions should be given higher priority in patient care. In addition, antiretroviral therapy should be readily accessible and affordable to HIV-infected individuals.
\end{abstract}

Keywords: Morbidity; Mortality; Respiratory tract diseases; Africa.

\section{Resumo}

Objetivo: Determinar a morbidade e a mortalidade relacionadas a doenças respiratórias em adultos atendidos em um hospital terciário na Nigéria. Métodos: Estudo retrospectivo com 183 pacientes adultos (> 15 anos) diagnosticados com doenças respiratórias, entre novembro de 2006 e outubro de 2008, no Centro Médico Federal em ldo-Ekiti, Nigéria. Resultados: Dos 183 pacientes estudados, 78 (42,6\%) eram do sexo masculino e 105 (57,4\%) do sexo feminino (razão entre homens e mulheres: 1:1,4). As doenças respiratórias foram predominantes na faixa etária entre 25 e 44 anos $(37,2 \%)$ e classe socioeconômica baixa $(81,4 \%)$. A forma pulmonar da TB foi a principal causa de morbidade (em 42,1\%), seguida por asma (em 17,5\%) e pneumonia (em 15,3\%). 0 câncer de pulmão foi raro (em somente $0,6 \%$ ). A TB pulmonar foi a principal causa de hospitalização devido à doença respiratória (em $32 \%$ ). A forma pulmonar da TB, asma, pneumonia e patologias da pleura foram mais frequentes no sexo feminino, ao passo que a DPOC foi mais frequente no sexo masculino. A comorbidade mais frequente foi a infecção por HIV (em 11,5\%). A média do tempo de hospitalização foi de 14 dias. A mortalidade foi 8,7\%; 50\% das mortes foram atribuídas à TB pulmonar, 25\% à doença pleural, 12,5\% à pneumonia e 6,25\% à exacerbação aguda da DPOC. A mortalidade foi maior em mulheres e na faixa etária de 25 a 44 anos. Conclusões: TB pulmonar, asma e pneumonia foram as principais causas de morbidade relacionada a doenças pulmonares. A forma pulmonar da TB foi a principal causa de mortalidade relacionada a doenças respiratórias na população adulta nigeriana estudada. Portanto, deve-se dar grande prioridade a essas doenças no atendimento desses pacientes. Além disso, a terapia antirretroviral deve ser de fácil acesso e pouco dispendiosa para indivíduos infectados com HIV.

Descritores: Morbidade; Mortalidade; Doenças respiratórias; África.

\footnotetext{
* Study carried out in the Department of Medicine, Federal Medical Centre, Ido-Ekiti, Nigeria. Kwara, Nigeria, 240001.

Tel +234 0803502 5771. E-mail: femuy1967@yahoo.co.uk

Financial support: None.

Submitted: 24 January 2009. Accepted, after review: 30 March 2009.

** A versão completa em português deste artigo está disponível em www.jornaldepneumologia.com.br
}

Correspondence to: Olufemi Olumuyiwa Desalu. Department of Medicine University of llorin Teaching Hospital, PMB 1459, 1lorin, 


\section{Introduction}

Respiratory diseases include a broad range of diseases, such as acute respiratory infections, pneumonia, obstructive lung diseases, pleural disease and pneumoconiosis, as well as malignancies of the respiratory tract. ${ }^{(1)}$ Respiratory diseases constitute a major cause of morbidity and mortality worldwide, the top five respiratory diseases accounting for $17.4 \%$ of all deaths and $13.3 \%$ of all disability-adjusted life years in the year 2000.(2) Lower respiratory tract infections, COPD, TB and lung cancer are among the ten leading causes of death worldwide. ${ }^{(2)}$ In view of the changing demographics, improvements in health care and increasing incomes, the burden of communicable diseases is likely to lessen, whereas the burden of chronic respiratory diseases will worsen due to smoking and the aging of the population. ${ }^{(2)}$ In the 1991-1992 period, respiratory diseases accounted for 6.5\% of all hospital admissions, as well as constituting the second leading cause of emergency admission to the hospital, in Britain. ${ }^{(3)}$ In addition, British physicians issued over 62 million prescriptions for the prevention and treatment of respiratory disease in 2004. ${ }^{(3,4)}$ Respiratory diseases constituted the third leading cause of hospitalization in Canada in 2001 and the fourth leading cause of disability in the United States in the 19911992 period. $^{(5,6)}$. In Nigeria, lower respiratory tract infections constituted the second leading cause of death in all age brackets in 2002, a year in which TB was the seventh leading cause of death, accounting for 4\% of all deaths. ${ }^{(7)}$ There have been few studies on respiratory diseaserelated morbidity and mortality in Africans. The aim of the present study was to determine the rates of such morbidity and mortality among adults treated at a tertiary-care hospital in Nigeria. Several studies on respiratory diseaserelated morbidity and mortality have relied on data from hospitalized cases. However, the use of such data might result in underestimation of morbidity and mortality. In the present study, we used a combination of data from outpatient cases and data from hospitalized cases, in order to avoid this problem.

\section{Methods}

This was a retrospective study carried out at the Federal Medical Centre, located in ldo-Ekiti in the South-West Zone of Nigeria, in December of 2008. The study setting was a tertiary-care medical facility that serves as a referral center for other district hospitals. The hospital also runs an internship program and a resident program. We retrieved the charts of all adult patients (> 15 years of age) diagnosed with respiratory diseases between November of 2006 and October of 2008. Of the 261 charts retrieved, 209 (84.3\%) presented complete data in relation to the investigations conducted. However, only $183(70.1 \%)$ met the criteria for a diagnosis of respiratory disease established by the Global Initiative for Asthma, the Global Initiative for Chronic Obstructive Lung Disease, the European Respiratory Society and the American Thoracic Society. ${ }^{(8-12)}$ Sociodemographic data, as well as data related to complaints, comorbid conditions, smoking history, hospital stays and outcomes, were extracted from patient charts. Ethical approval for the study was obtained from the Research Ethics Committee of the Federal Medical Centre, ldo-Ekiti, Nigeria.

\section{Statistical analysis}

Data were analyzed using the program Statistical Package for the Social Sciences, version 15.0 (SPSS Inc., Chicago, IL, USA). Descriptive and frequency statistics were obtained for the variables studied. The chi-square test was used in order to evaluate associations among the variables, and values of $p<0.05$ were considered significant.

\section{Results}

A total of 183 adult patients were enrolled in the study. Of those 183 patients, 125 (68.3\%)

Table 1 - Prevalence and ranking of respiratory diseases.

\begin{tabular}{lcc}
\hline \multicolumn{1}{c}{ Diseases } & $\mathrm{n}$ & $\%$ \\
\hline Pulmonary TB & 77 & 42.1 \\
Asthma & 32 & 17.5 \\
Pneumonia (CAP and HAP) & 28 & 15.3 \\
COPD & 21 & 11.5 \\
Pleural diseases & 14 & 7.7 \\
(pleural effusion and pneumothorax) & & \\
Unexplained cough & 4 & 2.2 \\
Bronchiectasis & 4 & 2.2 \\
Lung cancer & 1 & 0.6 \\
lnterstitial lung disease & 1 & 0.6 \\
Musculoskeletal chest pain & 1 & 0.6 \\
\hline
\end{tabular}

CAP: community-acquired pneumonia; and HAP: hospitalacquired pneumonia. 
were hospitalized, accounting for $8.7 \%$ of medical admissions and 2.9\% of total hospital admission over a period of 2 years. Patient ages ranged from 15 to 85 years. Of the 183 patients evaluated, $68(37.2 \%)$ were in the $25-44$ year age bracket, 58 (31.7\%) were in the 45-64 year age bracket, and 21 (11.5\%) were in the 15-24 year age bracket. There were 78 men and 105 women (42.6\% and $57.4 \%$ of the sample, respectively). The male:female ratio was 1:1.4. Based on the socioeconomic status classification validated for use in Nigeria, ${ }^{(13)} 74(40.4 \%)$ of the patients belonged to class V, $38(20.8 \%)$ belonged to class 111,14 (7.7\%) belonged to class 11,12 (6.6\%) belonged to class IV, and 8 (4.4\%) belonged to class 1 , and the remaining 33 patients $(18.1 \%)$ were not classifiable. Twenty-two (12.0\%) of the patients were smokers, and 30 (16.4\%) were consumers of alcoholic beverages.

Table 1 shows the most common respiratory diseases in our sample: pulmonary TB, with a prevalence of $42.1 \%$ (77 patients); asthma, with a prevalence of $17.5 \%$ (32 patients); pneumonia, with a prevalence of 15.3\% (28 patients); COPD, with a prevalence of $9.8 \%$ (21 patients); pleural diseases (pleural effusion and pneumothorax), with a prevalence of 7.7\% (14 patients); unexplained cough, with a prevalence of $2.2 \%$ (4 patients); bronchiectasis, with a prevalence of 2.2\% (4 patients); lung cancer, with a prevalence of $0.6 \%$ ( 1 patient); and interstitial lung disease, with a prevalence of $0.6 \%$ ( 1 patient). The prevalence and ranking of the various respiratory diseases is illustrated in Figure 1.

As can be seen in Figure 2, pulmonary TB and bronchial asthma were more common in the 25-44 year age bracket and less common in the 15-24 year age bracket; pneumonia was more common in the 45-64 year age bracket years and less common in the over-65 year age bracket; COPD was more common in age the over- 45 year age bracket and less common in the 25-44 year age bracket; and pleural pathology was most common in the under-45 year age bracket.

Figure 3 shows that pulmonary TB, asthma, pneumonia and pleural pathologies were more common in women than in men $(57.4 \%$ vs. $45.3 \%, 68.8 \%$ vs. $31.3 \%, 57.7 \%$ vs. $42.3 \%$ and 83.3\% vs. 16.7\%, respectively), whereas COPD and unexplained cough were more common in men $(33.3 \%$ vs. $66.7 \%$ and $25.0 \%$ vs. $75.0 \%$,

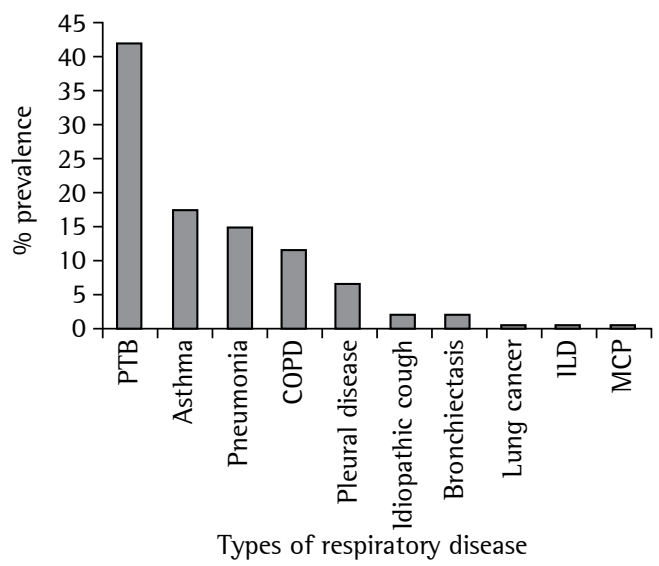

Figure 1 - Prevalence and ranking of adult respiratory diseases. PTB: pulmonary TB; lLD: interstitial lung disease; and MCP: musculoskeletal chest pain.

respectively). There was no gender-related difference in the frequency of bronchiectasis.

As can be seen in Table 2, the most common comorbidity in patients with respiratory disease was HIV infection, in 21 (11.5\%), followed by hypertension, in $9(4.9 \%)$, cor pulmonale, in 7 (3.8\%), septicemia, in $6(3.3 \%)$, diabetes mellitus, in $5(2.7 \%)$ and congestive heart failure, also in $5(2.7 \%)$.

Pulmonary TB was the leading cause of respiratory disease-related hospital admission, in $40(32 \%)$, followed by pneumonia, in $37(29.6 \%)$, asthma, in 21 (16.8\%), pleural disease, in 13 (10.4\%), COPD, in 12 (9.6\%),

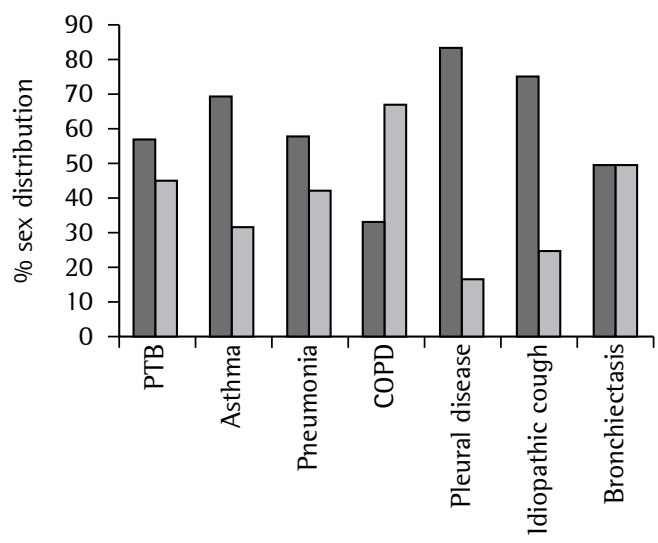

Types of respiratory diseases

$\square$ Female $\square$ Male

Figure 2 - Gender distribution of adult respiratory disease. PTB: pulmonary TB. 


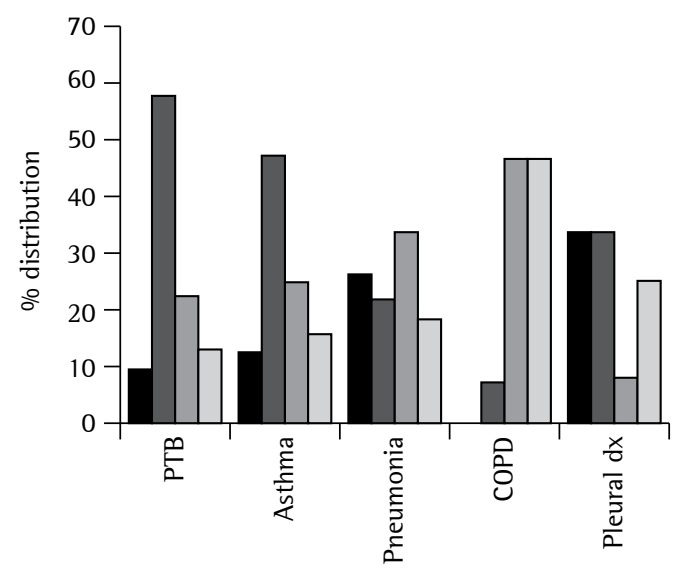

Types of respiratory disease

Age group 15-24 $\square$ Age group 45-64 Age group 25-44 $\square$ Age group 65+

Figure 3 - Age group distribution of five top ranking adult respiratory diseases. PTB: pulmonary TB.

interstitial lung disease, in $1(0.8 \%)$ and lung cancer, also in $1(0.8 \%)$.

The overall mortality rate was $8.7 \%$ (16 patients). Of the 183 patients evaluated, $8(4.4 \%)$ were discharged at their own request against medical advice, $3(1.6 \%)$ were referred to other hospitals, and $1(0.5 \%)$ was lost to follow up. Of the 16 recorded deaths, 8 (50.0\%) were attributed to pulmonary TB, 4 (25\%) were attributed to pleural disease, 2 (12.5\%) were attributed to pneumonia, 1 (6.25\%) was attributed to acute exacerbation of COPD, and the cause of death was unknown in 1 (6.25\%). Among those who died, 7 (43.8\%) were in the 25-44 year age range, 9 (56.3\%) were women and $6(37.5 \%)$ were HIV-infected. Among the hospitalized cases, the overall mean length of

Table $\mathbf{2}$ - Comorbid conditions in patients with respiratory disease.

\begin{tabular}{lrc}
\hline \multicolumn{1}{c}{ Comorbidity } & $\mathrm{n}$ & $\%$ \\
\hline HIV/AIDS & 21 & 11.5 \\
Hypertension & 9 & 4.9 \\
Cor-pulmonale & 7 & 3.8 \\
Septiceamia & 6 & 3.3 \\
Diabetes mellitus & 5 & 2.7 \\
Heart failure & 5 & 2.7 \\
Bronchiectasis & 4 & 2.2 \\
Hernia & 2 & 1.1 \\
Malignancy & 1 & 0.6 \\
\hline
\end{tabular}

hospital stay was 14 days, specific mean hospital stays being 5 days for pneumonia, 10 days for asthma, 11 days for COPD and 24 days for pleural effusion.

\section{Discussion}

This was a two-year retrospective study and analysis of respiratory diseases seen at a tertiary-care hospital in Nigeria. There have been no previous studies of the mortality and morbidity related to adult respiratory diseases in this part of Africa. The burden of HIV infection and poverty is greater on the African continent than in any other part of the world, and the impact that these two factors have on respiratory diseases is enormous. In the present study, respiratory diseases accounted for 2.9\% of all hospital admissions. In addition, $60 \%$ of the individuals presenting respiratory conditions were women, the male:female ratio being 1:1.4. Furthermore, the 25-44 year age bracket was the age bracket most often affected by respiratory diseases (accounting for 37.2\% of the cases) and the majority of the patients (81.4\%) were in the lower socioeconomic classes. Whereas COPD and unexplained cough were more common in the men, asthma, pulmonary $\mathrm{TB}$, pneumonia, pleural disease (effusion and pneumothorax) and bronchiectasis were more common in women. The gender distribution in our study was different from that seen in other studies conducted in Brazil, ${ }^{(14)}$ India ${ }^{(15)}$ and Saudi Arabia, ${ }^{(16)}$ in which respiratory diseases were found to be more common in men. This female predominance might be explained by the high burden of HIV infection in the female population and frequent exposure to indoor air pollution from the combustion of biomass fuels used for cooking. The biomass gases generated from the burning and combustion of organic material often impairs the physiological function of the lungs. In addition, men pay less attention to their health and less often seek medical attention, perhaps because men are usually major income earners for the family and will continue to work until their condition worsens and they are incapacitated. As a result of the severity of their condition and incapacitation, they often present as respiratory emergency cases. We also found that pulmonary TB was the leading cause of respiratory disease-related morbidity (in $42.1 \%$ ), which is consistent with the results of 
a study of adult lung diseases in Botswana. ${ }^{(17)}$ Our result is in contrast with those of studies conducted in India, ${ }^{(15)}$ in which asthma was found to be the leading cause of respiratory disease (in $26.5 \%$ ), and in Canada, in which asthma was found to account for $82.3 \%$ of all respiratory diseases. ${ }^{(5)}$ In the United Kingdom (UK), with the exception of the common cold, COPD is the leading cause of respiratory disease. ${ }^{(4)} \ln$ the present study, pulmonary TB was quite common because of the high prevalence of HIV/AIDS, widespread poverty, overcrowding and malnutrition in the study region. More than $90 \%$ of TB cases and TB-related deaths occur in the developing world, 75\% of those cases occurring in the most economically productive age bracket (15-54 years). ${ }^{(18)}$ On average, TB leads to a loss of three to four months of work time and of $20-30 \%$ of the annual household income and, if the patient dies of TB, an average of 15 years of lost income. ${ }^{(18)}$ In the Middle East, Western Europe and North America, pulmonary TB has been found to be common among migrants from developing countries. ${ }^{(4,5,16)}$

We also found pulmonary TB to be the leading cause of hospitalization for respiratory disease (in 32\%), followed by pneumonia (in 29.6\%), which supports reports from the Congo, where TB ranked first $(52.1 \%),{ }^{(19)}$ The leading cause of hospitalization in Brazil ${ }^{(14)}$ was pneumonia (in 47\%), whereas it was asthma (in 38.6\%) in Saudi Arabia. ${ }^{(16)} \mathrm{A}$ report from the UK revealed that $39 \%$ of bed days used for respiratory disease treatment are due to pneumonia and other acute lower respiratory infections. ${ }^{(5)}$ A survey conducted in Hong Kong ${ }^{(20)}$ showed that respiratory infections were a major cause of utilization of respiratory inpatient bed days. These differences in the ranking of respiratory diseases might be attributed to the interaction of environmental factors, smoking, HIV infection and poverty in the developing countries. In the present study, asthma was the second leading cause of respiratory diseases and the third leading cause of hospitalization, being more common among the women than among the men, which is in agreement with the findings of epidemiological studies conducted in Brazil, Iran, China and the USA. ${ }^{(14,21-23)}$ The female predominance can be attributed to the fact that, at birth, lung size is smaller in males than in females, whereas the inverse is true in adult- hood..$^{(8,24)}$ Asthma is a global problem, affecting an estimated 300 million people worldwide and accounting for 250,000 deaths annually. ${ }^{(8)}$ In the present study, pneumonia was the third leading cause of respiratory disease-related morbidity and the second leading cause of hospitalization. The disease was found to be more common in women and in the 45-64 year age bracket, a pattern of distribution that has also been reported in Saudi Arabia. ${ }^{(16)}$ The increased occurrence in the over-45 year age bracket has been attributed to the high prevalence of comorbid conditions that increase with age, such as hypertension and diabetes mellitus. In the United States, community-acquired pneumonia affects 5.6 million adults and causes 1.7 million hospitalizations annually, as well as being the sixth leading cause of death. ${ }^{(25)}$ In the present study, COPD was the fourth leading cause of respiratory disease-related morbidity and the fifth leading cause of hospitalization. Our study also revealed that COPD was more common in men and in the over-45 year age bracket, and this trend was consistent with those reported in studies conducted in Nigeria and Saudi Arabia. ${ }^{(16,26)}$ Male predominance among COPD patients was common in the past. ${ }^{(9)}$. $A$ recent epidemiological study of COPD in developed countries revealed that the occurrence of the disease is nearly equal between men and women. $(9,27)$ The changing pattern of COPD is a reflection of the increasing prevalence of smoking among women, and studies have revealed that women are more susceptible to tobacco smoke than men. ${ }^{(28)}$ An estimated 210 million people worldwide are affected by COPD, and 90\% of COPD deaths occur in low- or middle-income countries. ${ }^{(29)}$ The COPD-related mortality rate is projected to increase by more than 30\% over the next 10 years unless immediate action is taken to reduce the prevalence of underlying risk factors, especially smoking. ${ }^{(29)}$ More attention should be given to indoor air pollution (biomass smoke and other indoor gases), which has been implicated in the pathogenesis of COPD, rather than concentrating on smoking alone, ${ }^{(9,26)}$ since solid fuel is now used by a higher percentage of Nigerians (67\%) and other Africans (76\%). ${ }^{(7)}$ Further studies are needed in order to evaluate the impact of biomass combustion on the respiratory systems in this region of study. 
In the present study, pleural disease (effusion and pneumothorax) ranked fifth as a cause of respiratory disease-related morbidity and was fourth leading cause for hospitalization. It was more common in women and in the under-45 year age bracket. Bronchiectasis and unexplained cough constituted the sixth leading cause of respiratory disease, whereas lung cancer and interstitial lung diseases were, jointly, the seventh leading cause of respiratory disease. In terms of the occurrence of lung cancer, we found close similarities between our results and those of a study conducted in Botswana, in which the prevalence of lung cancer was $0.1 \% .{ }^{(17)}$ Lung cancer was uncommon in our study, perhaps due to a low prevalence of smoking in this population (12\%). In the UK, lung cancer was one of the most common cancers in adults, second only to prostate cancer in men and breast cancer in women; ${ }^{(4)}$ between 1998 and 2001, there were over 67,000 cases of lung cancer in men and nearly 42,000 cases of lung cancer in women. Lung cancer presents some of the lowest survival rates of the major cancers, five-year survival being only $6.3 \%$ among men and $7.5 \%$ among women. ${ }^{(3,4)}$ In Canada, 18,518 Canadians developed lung cancer in 1997: 11,203 men and 7,315 women. Sixty-five percent of new cases were among individuals aged $\geq 65$ years, compared with $32 \%$ for those aged $45-64$ years and 3\% for those under 45 years of age..$^{(5)}$ In most of Nigeria, cases of lung cancer are often mistakenly treated as smear-negative for pulmonary TB, perhaps because of unavailable or malfunctioning equipment, poor diagnostic services and low index of suspicion of lung cancer among physicians.

It is of note that certain diseases, such as sarcoidosis, Pneumocystis jirovecii pneumonia, collagen lung diseases and pneumoconiosis, were rare in the present study, likely due to a lack of awareness among physicians, as well as to overzealousness and the tendency to diagnose any abnormal radiographic findings as pulmonary TB and initiate treatment as soon as possible. We also found that the most common comorbidity in patients with respiratory disease was HIV infection (in 11.5\%); followed by hypertension (in 4.9\%), whereas the most common such comorbidities in Saudi Arabia were diabetes mellitus (in 22.8\%) and hypertension (in 15.1\%)s. Nontreatment of HIV infection leads to increased susceptibility to opportunistic infections. The epidemics of TB and other respiratory infections in many countries, especially those in sub-Saharan Africa, Asia and South America, are sustained by HIV infection. In areas of high HIV prevalence, many HIV-infected individuals develop $\mathrm{TB}$, and many $\mathrm{TB}$ patients are co-infected with HIV. The standard treatment for HIV infection is highly active antiretroviral therapy (HAART). Unfortunately, only a very small proportion of all HIV-infected individuals have access to HAART. In the present study, the majority of the HIV-infected individuals were on HAART. In 2004, 2.1\% of people living with HIV infection in Nigeria were on HAART, compared with $26.4 \% \quad(198,000$ of the 750,000 adult Nigerians requiring HAART, based on the World Health Organization Joint United Nations Program on HIV/AIDS criteria) in 2007. ${ }^{(30)}$ Although there was an increase from $2.1 \%$ to $26.4 \%$ in the percentage of people receiving HAART, the number of people living with HIV/ AIDS who were not on treatment was still high; this is unacceptable and fails to meet the World Health Organization target .Therefore, we need to increase the accessibility and availability of antiretroviral therapy for Nigerians with HIV/ AIDS.

The overall mean length of hospital stay for the patients evaluated in the present study was 2 weeks, compared with 1-2 weeks in Saudi Arabia. ${ }^{(16)}$ Overall mortality was $8.7 \%$, half of the deaths $(50 \%)$ being attributed to pulmonary $\mathrm{TB}$, as has been reported for other African countries. ${ }^{(17,19)}$ In Canada, lung cancer was the leading cause of respiratory disease-related mortality (88.1\%), whereas cancer of the lung, trachea and bronchus were the leading causes of respiratory disease-related deaths in the UK, accounting for 33,088 deaths. ${ }^{(4,5)}$

This was a retrospective study and, as such, has certain inherent limitations, such as poor or incomplete medical record keeping, missing data and lack of essential, specific diagnostic facilities, as well as poor follow-up clinic visitation. Despite these limitations, we were able to determine the rates of respiratory disease-related morbidity and mortality among adults treated at a tertiary-care hospital in Nigeria.

On the African continent, the problems related to HIV infection and socioeconomic inequality are probably greater than in any other part of 
the world. The synergistic effect of HIV infection, tobacco smoking, environmental pollution, poverty and poor diagnostic services, together with, in some cases, the collapse of the health infrastructure due to severe socioeconomic crisis or civil unrest, significantly increases the risk of developing respiratory diseases. In the present study, pulmonary $\mathrm{TB}$, asthma and pneumonia constituted the leading cause of respiratory disease-related morbidity and hospitalization in adult Nigerians. Pulmonary TB was the leading cause of mortality. Infection with HIV was the most common comorbidity (in 11.5\%). Considering the resources at the disposal of many poor countries, this review will aid epidemiologists, health authorities and policy makers, providing the opportunity to channel their small financial resources to the area of need. Therefore, these respiratory conditions should be given higher priority in patient care, and antiretroviral agents should be readily accessible and available to HIV-infected individuals.

\section{Acknowledgments}

We would like to recognize the efforts of the staff of the Health Records Department of the Federal Medical Centre in ldo-Ekiti, Nigeria, as well as the medical interns for their assistance in retrieving the relevant patient charts.

\section{References}

1. World Health Organization WHO [homepage on the Internet]. Geneva: World Health Organization. c2008-01 [cited 2008 Dec 29]. Available from http://www.who.it

2. World Health Organization. WHO strategy for prevention and control of chronic respiratory diseases. Geneva: WHO; 2002.

3. Lung and Asthma Information Agency [homepage on the Internet]. London: Community Health Sciences Division, St George's University of London. [cited 2008 Dec 29]. The burden of respiratory disease 95/3. Available from: http://www.laia.ac.uk/95_3/95_3.htm

4. The British Thoracic Society. The Burden of Lung Disease 2006 - A statistics report from British Thoracic Society. London: The British Thoracic Society; 2006.

5. Canadian Institute for Health Information. Canadian Lung Association. Health Canada. Statistics Canada. Respiratory Disease in Canada. Ottawa: Public Health Agency of Canada; 2001.

6. Centers for Disease Control and Prevention (CDC). Prevalence of disabilities and associated health conditions--United States, 1991-1992. MWR Morb Mortal Wkly Rep. 1994;43(40):730-1, 737-9.

7. World Health Organization [homepage on the Internet]. Geneva: World Health Organization. Country Health System Fact Sheet 2006 - Nigeria. Available from: http://www.afro.who.int/home/countries/fact_sheets/ nigeria.pdf

8. Global Initiative for Asthma. Global Strategy for Asthma Management and Prevention - 2007 updated. Geneva: Global Initiative for Asthma; 2007.

9. Global Initiative for Chronic Obstructive Lung Disease. Global Strategy for diagnosis, Management and Prevention on Chronic Obstructive lung Disease (update 2008). Bethesda: Global Initiative for Chronic Obstructive Lung Disease; 2008.

10. European Respiratory Society [homepage on the Internet]. Geneva: European Respiratory Society. [updated 2009; cited 2009 Jan 9]. Guidelines. Available from: http:// www.ers-education.org/pages/default.aspx?id=725

11. American Thoracic Society [homepage on the Internet]. Danvers: American Thoracic Society. [updated 2009; cited 2009 Jan 9]. ATS Documents: Statements, Guidelines \& Reports. Available from http://www. thoracic.org/section/ publication/statements/index.html

12. American College of Chest Physicians [homepage on the Internet]. Northbrook: American College of Chest Physicians [updated 2009; cited 2009 Jan 9]. Current Guidelines. Available from: http://www.chestnet.org/ education/hsp/currentGuidelines.php

13. Olusanya O, Okpere E, Ezimokhai M. The importance of social class in voluntary fertility control in a developing country. West Afr J Med. 1985;4:205-12.

14. Toyoshima MT, lto GM, Gouveia N. Trends in morbidity for respiratory diseases among hospitalized patients in the city of São Paulo [Article in Portuguese]. Rev Assoc Med Bras. 2005;51(4):209-13.

15. Dasgupta A, Bagchi A, Nag S, Bardhan S, Bhattacharyya P. Profile of respiratory problems in patients presenting to a referral pulmonary clinic. Lung India. 2008;25:4-7

16. Omer S. Alamoudi. .Prevalence of respiratory diseases in hospitalized patients in Saudi Arabia: A five years study 1996-2000. Ann Thorac Med. 2006;1(2):76-80.

17. Steen TW, Aruwa JE, Hone NM. The epidemiology of adult lung disease in Botswana. Int $\mathrm{J}$ Tuberc Lung Dis. 2001;5(8):775-82.

18. Ahlburg DA, Stop TB lnitiative (World Health Organization). The economic impacts of tuberculosis. Geneva: Stop TB Initiative, World Health Organization; 2000.

19. Mboussa J. Respiratory diseases at hospitals in Brazzaville, Congo [Article in French]. Rev Pneumol Clin. 1990;46(2):61-5.

20. Chan-Yeung M, Lai CK, Chan KS, Cheung AH, Yao TJ, Ho AS, et al. The burden of lung disease in Hong Kong: a report from the Hong Kong Thoracic Society. Respirology. 2008;13 Suppl 4:S133-65. Erratum in: Respirology. 2009;14(1):150.

21. Boskabady MH, Kolahdoz GH. Prevalence of asthma symptoms among the adult population in the city of Mashhad (north-east of Iran). Respirology. 2002;7(3):267-72.

22. Chan-Yeung M, Zhan LX, Tu DH, Li B, He GX, Kauppinen $\mathrm{R}$, et al. The prevalence of asthma and asthma-like symptoms among adults in rural Beijing, China. Eur Respir J. 2002;19(5):853-8.

23. Schatz M, Clark S, Camargo CA Jr. Sex differences in the presentation and course of asthma hospitalizations. Chest. 2006;129(1):50-5.

24. Martinez FD, Wright AL, Taussig LM, Holberg CJ, Halonen M, Morgan WJ. Asthma and wheezing in 
the first six years of life. The Group Health Medical Associates. N Engl J Med. 1995;332(3):133-8.

25. Mandell LA. Community-acquired pneumonia. Etiology, epidemiology, and treatment. Chest. 1995;108(2 Suppl):35S-42S.

26. Erhabor GE, Kolawole OA. Chronic obstructive pulmonary disease: a ten-year review of clinical features in O.A.U.T.H.C., lle-lfe. Niger J Med. 2002;11(3):101-4.

27. Chen JC, Mannino DM. Worldwide epidemiology of chronic obstructive pulmonary disease. Curr Opin Pulm Med. 1999;5(2):93-9.

28. Silverman EK, Weiss ST, Drazen JM, Chapman HA, Carey $\mathrm{V}$, Campbell EJ, et al. Gender-related differences in severe, early-onset chronic obstructive pulmonary disease. Am J Respir Crit Care Med. 2000;162(6):2152-8.

29. World Health Organization [homepage on the Internet]. Geneva: World Health Organization. [updated 2008; cited 2009 Jan 9]. Chronic obstructive pulmonary disease (COPD) - Fact sheet No 315 May 2008. Available from: http://www.who.int/mediacentre/factsheets/fs315/en

30. World Health Organization [homepage on the Internet]. Geneva: World Health Organization. [cited 2009 Jan 9]. Epidemiological Fact Sheet on HIV and AIDS - Core data on epidemiology and response - Nigeria - 2008 Update. Available from: http://apps.who.int/globalatlas/ predefinedReports/EFS2008/full/EFS2008_NG.pdf

\section{About the authors}

\section{Olufemi Olumuyiwa Desalu}

Consultant Pulmonologist. Department of Medicine, University of llorin Teaching Hospital, llorin, Nigeria.

\section{Joshua Afolayan Oluwafemi}

Medical Officer. Department of Medicine, Federal Medical Centre, ldo-Ekiti, Nigeria.

\section{Ololade Ojo}

Consultant Physician. Department of Community Medicine, Federal Medical Centre, ldo-Ekiti, Nigeria. 